\title{
BIODIESEL DE SOJA - REAÇÃo DE TRANSESTERIFICAÇÃo PARA AULAS PRÁTICAS DE QUÍMICA ORGÂNICA
}

Regina Geris*, Nádia Alessandra Carmo dos Santos, Bruno Andrade Amaral, Isabelle de Souza Maia, Vinicius Dourado Castro e José Roque Mota Carvalho

Instituto de Química, Universidade Federal da Bahia, Campus de Ondina, Rua Barão de Geremoabo, s/n, 40170-290

Salvador - BA, Brasil

Recebido em 18/4/06; aceito em 9/11/06; publicado na web em 14/5/07

\begin{abstract}
BIODIESEL FROM SOYBEAN OIL - EXPERIMENTAL PROCEDURE OF TRANSESTERIFICATION FOR ORGANIC CHEMISTRY LABORATORIES. The transesterification procedure of triacylglycerides from soybean oil (in natura and waste oil) to give biodiesel was adapted to semi-micro laboratory scale as an additional experimental technique of nucleophilic acyl substitution for undergraduate courses in Chemistry and related areas.
\end{abstract}

Keywords: biodiesel; transesterification; undergraduate experiment.

\section{INTRODUÇÃO}

O objetivo deste manuscrito é propor um experimento de Química Orgânica Experimental envolvendo a obtenção de biodiesel a partir de óleo de soja in natura e de óleo de soja usado em frituras, como um experimento alternativo aos já existentes destinados ao estudo das reações de esterificação.

Um dos tópicos abordados nas aulas práticas de Química Orgânica é a reação de substituição nucleofílica acílica, apresentada através das reações de esterificação e transesterificação. De modo geral, no ensino dessas reações se utilizam compostos de partida simples e de baixo custo, como por ex., ácido benzóico, ácido salicílico, anilina para preparação do benzoato de metila, ácido acetilsalicílico e acetanilida, respectivamente ${ }^{1,2}$. Essas reações apresentam grande simplicidade em suas execuções, além de se adequarem à carga horária de uma aula prática (em média 4 h/aula).

Entretanto, é importante a realização de experimentos laboratoriais que estejam em sintonia com as pesquisas mais recentes envolvendo novos desafios tecnológicos, proporcionando aos alunos de graduação em Química e áreas correlatas, a aplicação de seus conhecimentos básicos, despertando o interesse científico ou tecnológico nos mesmos.

No presente trabalho, descrevemos um procedimento bastante simples de obtenção do biodiesel, possível de ser conduzido em um laboratório experimental de química em, no máximo, 8 h (2 aulas práticas de $4 \mathrm{~h}$, na qual, a primeira é destinada ao trabalho de síntese e a outra para discussão e análise dos resultados obtidos). Inicialmente os ensaios pilotos foram otimizados com 4 alunos de iniciação científica, co-autores do trabalho e, posteriormente, aplicado na aula prática de Química Orgânica Experimental I.

\section{Biodiesel}

Combustíveis a diesel são de vital importância no setor econômico de um país em desenvolvimento. A alta demanda de energia no mundo industrializado e no setor doméstico, bem como os problemas de poluição causados devido ao vasto uso desses combustíveis, têm resultado em uma crescente necessidade de desenvolver

*e-mail: rmgeris@ufba.br fontes de energias renováveis sem limites de duração e de menor impacto ambiental que os meios tradicionais existentes ${ }^{3}$, estimulando, assim, recentes interesses na busca de fontes alternativas para combustíveis à base de petróleo.

Uma alternativa possível ao combustível fóssil é o uso de óleos de origem vegetal, os quais podem ser denominados de "biodiesel"3. Quimicamente, os óleos e gorduras animais e vegetais consistem de moléculas de triacilglicerídeos, as quais são constituídas de três ácidos graxos de cadeia longa ligados na forma de ésteres a uma molécula de glicerol. Esses ácidos graxos variam na extensão da cadeia carbônica, no número, orientação e posição das ligações duplas ${ }^{3,4}$. Entretanto, o uso de óleos vegetais como combustível alternativo para equipamentos a diesel é considerado insatisfatório e impraticável, por apresentar uma série de fatores limitantes, como alta viscosidade, conteúdos de ácidos graxos livres, combustão incompleta e baixa volatilidade que resulta na formação de depósitos nos injetores de combustível das máquinas ${ }^{3-5}$. Para superá-los, os triacilglicerídeos devem ser derivatizados para se tornarem compatíveis com as máquinas existentes ${ }^{4}$. Várias alternativas foram consideradas para reduzir esses problemas, como por ex., diluição; emulsificação através da formação de micro-emulsões usando como solventes, metanol, etanol ou butanol; pirólise; craqueamento catalítico empregando sais metálicos (ex. $\mathrm{SiO}_{2} / \mathrm{Al}_{2} \mathrm{O}_{3}$ a $450{ }^{\circ} \mathrm{C}$ ); transesterificação com etanol ou metanol ${ }^{4-6}$.

Das várias metodologias descritas na literatura para obtenção do biodiesel, a transesterificação de óleos vegetais é atualmente o método de escolha, principalmente porque as características físicas dos ésteres de ácidos graxos são muito próximas daquelas do diesel ${ }^{4,5}$. Além disso, este processo relativamente simples reduz a massa molecular para um terço em relação aos triacilglicerídeos, como também reduz a viscosidade e aumenta a volatilidade ${ }^{6}$.

Embora o conceito sobre biodiesel esteja sob discussão, este termo pode ser empregado para descrever ésteres de ácidos graxos de cadeia longa (monoésteres alquílicos) derivados de fontes renováveis, tais como óleos vegetais e gorduras animais ${ }^{3,7,8}$. O biodiesel surgiu como uma alternativa para a substituição ao óleo diesel, contribuindo para minimizar a dependência das importações do petróleo, como também para a redução da poluição ambiental, através da diminuição das emissões de gases poluentes. Esta fonte renovável de energia vem sendo amplamente pesquisada em diversos países ${ }^{8}$. 
O Brasil é um país que contém grandes plantações de oleaginosas e, conseqüientemente, usufrui de uma diversidade de opções para produção de biodiesel a partir de plantas como palma, babaçu, soja, girassol, amendoim, mamona e dendê. Em 14/9/2004, o Congresso Nacional aprovou a Medida Provisória 214, abrindo a possibilidade do uso do biodiesel fora do campo de pesquisa, com fins efetivos de uso em larga escala ${ }^{9}$. Posteriormente, em 13/1/2005, a lei $\mathrm{N}^{\circ} 11.097$ regularizou a introdução do mesmo no território brasileiro, estipulando a meta de $5 \%$ de adição do produto ao óleo diesel em um prazo máximo de 8 anos $^{9}$. Conseqüentemente, grandes investimentos serão realizados nessa área, principalmente nas regiões Norte e Nordeste, como por ex., o de US\$ 381 milhões oriundos da Petrobrás para investir no biodiesel até 2010. Somados aos aportes dos parceiros, os projetos poderão chegar a US\$ 1 bilhão ${ }^{10}$.

\section{Transesterificação}

Transesterificação é um termo geral usado para descrever uma importante classe de reações orgânicas onde um éster é transformado em outro através da troca do resíduo alcoxila ${ }^{5,11}$. Quando o éster original reage com um álcool, o processo de transesterificação é denominado alcoólise (Figura 1a). Esta reação é reversível e prossegue essencialmente misturando os reagentes. Contudo, a presença de um catalisador (ácido ou base) acelera consideravelmente esta conversão, como também contribui para aumentar o rendimento da mesma ${ }^{3-5}$.

$\mathrm{Na}$ transesterificação de óleos vegetais, um triacilglicerídeo reage com um álcool na presença de uma base ou ácido forte, produzindo uma mistura de ésteres de ácidos graxos e glicerol, conforme esquematizado na Figura 1b. O processo geral é uma seqüência de três reações consecutivas, na qual mono e diacilglicerídeos são formados como intermediários ${ }^{5}$. Para uma transesterificação estequiometricamente completa, uma proporção molar 3:1 de álcool por triacilglicerídeo é necessária ${ }^{3-5}$. Entretanto, devido ao caráter reversível da reação, o agente transesterificante (álcool) geralmente é adicionado em excesso contribuindo, assim, para aumentar o rendimento do éster, bem como permitir a sua separação do glicerol formado ${ }^{3,12}$.

$$
\begin{aligned}
& \text { a) } \stackrel{\stackrel{\mathrm{O}}{\mathrm{C}}-\mathrm{OR}}{\mathrm{R}}+\mathrm{R} 2-\mathrm{OH} \rightleftharpoons \mathrm{O} \\
& \begin{array}{llll}
\text { éster } 1 & \text { álcool } 1 & \text { éster } 2 & \text { álcool } 2
\end{array}
\end{aligned}
$$

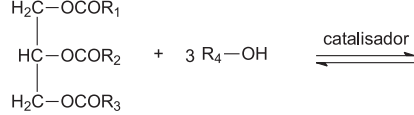

$$
\begin{aligned}
& \text { Triacilglicerideo } \\
& \begin{array}{c}
\text { Mistura de Glicerol } \\
\text { ésteres }
\end{array}
\end{aligned}
$$

Uma grande variedade de óleos vegetais pode ser utilizada para preparação do biodiesel. Entre os mais estudados encontram-se os óleos de soja, girassol, palma, amêndoa, babaçu, cevada e $\operatorname{coco}^{5,6} \mathrm{e}$ a composição diversificada de seus ácidos graxos é um fator que influencia nas propriedades do biodiesel ${ }^{6}$. Óleos vegetais usados também são considerados como uma fonte promissora para obtenção do biocombustível, em função do baixo custo e por envolver reciclagem de resíduos ${ }^{13}$. O produto obtido é comparável com o biodiesel obtido a partir do óleo refinado ${ }^{14}$.

Com relação ao agente transesterificante, o processo reacional ocorre preferencialmente com álcoois de baixa massa molecular, como por ex., metanol, etanol, propanol, butanol e álcool amílico ${ }^{15}$, mas metanol e etanol são os mais freqüentemente empregados ${ }^{4}$. Metanol é o mais utilizado devido ao seu baixo custo na maioria dos países e às suas vantagens físicas e químicas (polaridade, álcool de cadeia mais curta, reage rapidamente com o triacilglicerídeo e dissolve facilmente o catalisador básico $)^{4}$. Além disso, permite a separação simultânea do glicerol $^{5}$. A mesma reação usando etanol é mais complicada, pois requer um álcool anidro, bem como um óleo com baixo teor de água para levar à separação do glicerol ${ }^{5}$.

Este procedimento pode ser realizado tanto em meio ácido como em meio básico ou utilizando enzimas. Entre os catalisadores básicos estão os hidróxidos de metais alcalinos, carbonatos e alcóxidos de metais alcalinos (metóxido de sódio, etóxido de sódio, propóxido de sódio e butóxido de sódio $)^{4}$. A maior parte dos trabalhos descritos na literatura emprega catalisadores básicos, tais como $\mathrm{KOH}$ e $\mathrm{NaOH}$ onde foram observados maior rendimento e seletividade ${ }^{16}$. No entanto, outros catalisadores básicos não iônicos podem ser usados na transesterificação dos triacilglicerídeos, evitando a formação de subprodutos indesejáveis como os sabões, entre eles trietilamina, piperidina, guanidinas ${ }^{5}$.

Ácido sulfúrico, ácidos sulfônicos e ácido clorídrico são geralmente empregados como catalisadores ácidos. A conversão enzimática de óleos vegetais em biodiesel oferece uma opção ambientalmente mais atrativa que os processos convencionais ${ }^{17,18}$. Enzimas hidrolíticas como as lipases são usadas como biocatalisadores, embora o processo enzimático não tenha sido desenvolvido comercialmente $\mathrm{e}^{5}$.

Outros tipos de transesterificações também se encontram descritos na literatura. Aos leitores recomendamos artigos de revisão que discutem essas metodologias, entre elas a transesterificação com álcoois ramificados, transesterificação in situ, metanólise direta empregando lipases imobilizadas em dióxido de carbono supercrítico, catálise heterogênea utilizando polímeros orgânicos incorporados com catalisadores ${ }^{3-6}$.

\section{PARTE EXPERIMENTAL}

\section{Reagentes e equipamentos}

\section{Reagentes}

Óleo de soja comercial; óleo de soja usado na fritura de salgadinhos; metóxido de potássio recentemente preparado; hidróxido de potássio (Synth); sulfato de sódio anidro (Quimex); iodo ressublimado (Merck); éter de petróleo (Quimex); éter dietílico (Quimex); ácido acético glacial (Mallinckrodt); ácido oléico (Merck); oleato de metila (sintetizado no laboratório); clorofórmio deuterado (Cambridge Isotope Laboratories, Inc).

\section{Equipamentos}

Densímetro (Arba) e espectrômetro de RMN Varian (Gemini 300).

\section{Metóxido de potássio}

A solução de metóxido de potássio foi preparada dissolvendose $1,5 \mathrm{~g}$ de hidróxido de potássio $(\mathrm{KOH})$ em $35 \mathrm{~mL}$ de metanol com o auxílio de agitação e controle de temperatura $\left(45^{\circ} \mathrm{C}\right)$ até a completa dissolução de $\mathrm{KOH}$. O volume de metanol e a massa de $\mathrm{KOH}$ para a reação de transesterificação têm por finalidade alcançar um melhor rendimento da produção do éster ${ }^{19}$. Segundo Rabelo ${ }^{19}$ o melhor rendimento ocorreu com 1,5 g de $\mathrm{KOH}$ e $35 \%$ de metanol em relação a $100 \mathrm{~mL}$ de óleo.

Observação: Essa solução deve ser manipulada cuidadosamente utilizando a capela e os alunos portando seus EPIs (equipamen- 
tos de proteção individual), devido ao caráter corrosivo da base e à toxicidade do metanol.

\section{A reação de transesterificação}

Em um balão de fundo chato $(500 \mathrm{~mL})$ foram adicionados 100 $\mathrm{mL}$ do óleo de soja (in natura ou usado em frituras, sendo este último previamente filtrado através de algodão para remoção de resíduos sólidos). Esse material foi aquecido em banho-maria, sob agitação com o auxílio de uma barra magnética, até atingir a temperatura de $45^{\circ} \mathrm{C}$. Em seguida, foi adicionada a solução de metóxido de potássio recentemente preparada, e a mistura reacional permaneceu 10 min a $45^{\circ} \mathrm{C}$ sob agitação.

\section{Elaboração do biodiesel}

Posteriormente, a mistura reacional foi transferida para um funil de separação para permitir a decantação e separação das fases: superior contendo biodiesel e inferior composta de glicerol, sabões, excesso de base e álcool (tempo de espera para separação das fases: $15 \mathrm{~min}$ ). A fase inferior foi recolhida em uma proveta de 50 $\mathrm{mL}$ e o volume obtido foi anotado. Este material foi submetido à destilação a $80{ }^{\circ} \mathrm{C}$ para recuperar o álcool que não reagiu.

$\mathrm{O}$ volume de biodiesel (fase superior) foi medido utilizando-se uma proveta de $250 \mathrm{~mL}$ e então retornado ao funil de separação para os procedimentos de lavagem: inicialmente com $50 \mathrm{~mL}$ da solução aquosa de ácido clorídrico a 0,5\% (v/v); em seguida, uma lavagem com $50 \mathrm{~mL}$ de solução saturada de $\mathrm{NaCl}$ e, finalmente, com $50 \mathrm{~mL}$ de água destilada. A ausência do catalisador básico no biodiesel pode ser confirmada através da medida do $\mathrm{pH}$ da última água de lavagem, a qual deve estar neutra. Nos casos em que houve a formação de emulsão, a mesma foi desfeita com auxílio de um bastão de vidro, agitando-se lentamente a camada emulsificada. $\mathrm{O}$ tempo gasto para os procedimentos de lavagem foi de $01 \mathrm{~h} 30 \mathrm{~min}$. Para remoção dos traços de umidade o biodiesel foi filtrado utilizando-se sulfato de sódio anidro e transferido para uma proveta de $250 \mathrm{~mL}$ para medição do volume. O biodiesel aparece como um líquido límpido de coloração amarela.

\section{Análise do biodiesel}

O produto final da reação foi analisado qualitativamente através de cromatografia em camada delgada (CCD), densidade, RMN ${ }^{1} \mathrm{H}$ e teste de combustão.

O biodiesel e o material de partida foram dissolvidos em éter de petróleo e aplicados sobre a placa de CCD contendo sílica como fase estacionária. Utilizou-se como fase móvel uma mistura ternária de éter de petróleo:éter etílico:ácido acético (80:19:1). Após a eluição, a cromatoplaca foi revelada com vapores de iodo. Foram empregados como padrões cromatográficos ácido oléico e oleato de metila. Os valores de fatores de retenção $\left(\mathrm{R}_{\mathrm{f}}\right)$ do biodiesel, dos padrões e do óleo foram comparados.

Ambos, óleo de soja e produto final, foram analisados por RMN ${ }^{1} \mathrm{H}$. Sinais correspondentes à presença de triacilglicerídeos no material de partida e a ausência dos mesmos no produto, juntamente com o aparecimento do sinal que caracteriza os ésteres metílicos confirmam a obtenção do biodiesel. Utilizou-se clorofórmio deuterado como solvente e tetrametilsilano como padrão interno de referência.

O teste de combustão foi realizado utilizando cadinhos de porcelana contendo chumaços de algodão embebidos com óleo de soja, biodiesel, metanol e glicerina. Como fonte de calor para promoção da combustão foi usado um palito de fósforo. A densidade dos produtos aferida utilizou-se um densímetro (Arba) de faixa 0,850 - 0,900.

\section{RESULTADOS E DISCUSSÃO}

Uma série de metodologias para obtenção de biodiesel encontra-se disponível na literatura-10,12-19. Nelas são discutidas as variáveis que influenciam a eficiência do processo, bem como a qualidade do produto formado, como por ex., a quantidade de material catalítico, a razão molar álcool/óleo vegetal, a intensidade da agitação mecânica, a pureza dos reagentes, o teor de ácidos graxos livres no material de partida e o tempo reacional. Visando preparar um experimento prático que pudesse ser realizado por alunos de graduação durante uma aula prática de Química Orgânica, várias otimizações e adequações foram realizadas nos experimentos-piloto feitos pelos alunos de iniciação científica e, posteriormente, foi desenvolvida uma metodologia rápida, simples e de baixo custo para obtenção do biodiesel.

O método envolveu a transesterificação do óleo de soja (in natura e usado em frituras) utilizando como agente transesterificante o metanol em condições básicas com hidróxido de potássio a $45^{\circ} \mathrm{C}$. Embora o uso da solução saturada de $\mathrm{NaCl}$ não seja um procedimento adotado na lavagem durante o processo de obtenção do biodiesel, optamos por utilizar a fim de evitar a formação de emulsão e dificultar o processo de separação do biodiesel.

As principais etapas da transesterificação dos óleos vegetais catalisada por bases são apresentadas na Figura 2. O primeiro passo é a reação da base com metanol, produzindo alcóxido (base conjugada) e água (ácido conjugado). O alcóxido, agindo como nucleófilo, ataca o átomo de carbono deficiente em elétrons do grupo carbonila do triacilglicerídeo, conduzindo à formação do intermediário tetraédrico; a ruptura da ligação entre carbono e oxigênio do glicerídeo no intermediário tetraédrico conduz ao produto carbonilado (éster metílico) e ao diacilglicerídeo, este último formado após a remoção do átomo de hidrogênio do metanol, obtendo o ânion metóxido, permitindo a continuidade do processo reacional. Diacilglicerídeos e monoacilglicerídeos são convertidos pelo mesmo mecanismo para a mistura de ésteres metílicos e glicerol.

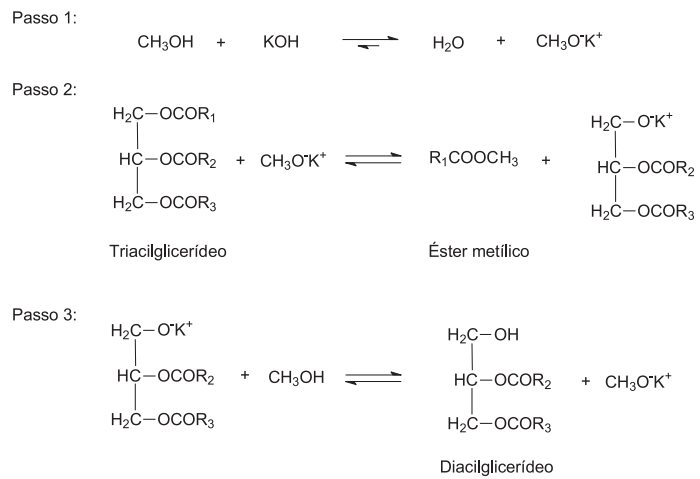

Figura 2. Equações da reação de transesterificação de um triacilglicerídeo com metanol catalisada por hidróxido de potássio

Vale ressaltar que a reação do hidróxido de potássio com o álcool leva à formação de água e, na presença do catalisador básico, poderá levar à hidrólise de algum éster produzido, com consequiente formação de sabão (Figura 3). Esta saponificação indesejável reduz o rendimento do éster e dificulta consideravelmente a recuperação do glicerol, devido à formação de emulsão ${ }^{5}$. Além disso, o consumo do catalisador reduz a eficiência da reação. Portanto, para uma transesterificação catalisada por bases, ambos os óleos e álcool devem ser isentos de água ${ }^{4}$. Um baixo teor de ácidos graxos livres no óleo também é necessário se o processo de alcoólise ocorrer por catálise básica. Óleos vegetais que conte- 
nham alto teor de ácidos graxos livres ou água devem ser processados via catálise ácida ${ }^{4}$.

$$
\stackrel{\mathrm{O}}{\mathrm{II}}-\mathrm{O}-\mathrm{OR}_{1}+\mathrm{KOH} \underset{\mathrm{H}_{2} \mathrm{O}}{\rightleftharpoons} \stackrel{\mathrm{O}}{\mathrm{II}}-\mathrm{O}^{-} \mathrm{K}^{+}+\mathrm{R}_{1}-\mathrm{OH}
$$

Figura 3. Principal reação secundária durante a transesterificação: reação de saponificação

Em nossos experimentos utilizamos o metanol como agente transesterificante, ao invés de etanol, para facilitar o procedimento de separação do biodiesel de glicerol. Embora menos reativo que o metanol e com os problemas tecnológicos envolvidos, o etanol, no Brasil apresenta um grande potencial devido a sua baixa toxicidade e fácil disponibilidade ${ }^{6}$. Dessa forma, o biodiesel obtido a partir de óleos vegetais e etanol seria considerado como um biocombustível obtido a partir de fontes totalmente renováveis de energia.

Nas condições utilizadas no experimento proposto, os biodieseis obtidos a partir do óleo de soja in natura e usado em frituras apresentaram aspecto límpido de coloração amarela, pH neutro $(7,0)$ e densidade de $0,877 \mathrm{~g} / \mathrm{mL}$ a $25^{\circ} \mathrm{C}$. A eficiência da reação foi monitorada utilizando $\mathrm{CCD}$ e $\mathrm{RMN}{ }^{1} \mathrm{H}$, pois o produto final poderia possuir alguns traços do material de partida.

A análise do cromatograma sugeriu a conversão total dos triacilglicerídeos em ésteres metílicos, visto a presença de mancha única na cromatoplaca sem vestígios do material de partida. Além disso, os valores de $\mathrm{R}_{\mathrm{f}}$ dos produtos foram comparados com padrões de ácido oleico, éster metílico e triacilglicerídeo, os quais se encontram descritos na Tabela 1.

Tabela 1. Valores de $\mathrm{R}_{\mathrm{f}}$ de padrões e do biodiesel formado a partir de óleo de soja in natura e usado em frituras

\begin{tabular}{lc}
\hline Substância & $\mathrm{R}_{\mathrm{f}}{ }^{*}$ \\
\hline Óleo in natura (triacilglicerídeos) & 0,67 \\
Óleo usado em fritura (triacilglicerídeos) & 0,67 \\
Biodiesel (óleo in natura) & 0,82 \\
Biodiesel (óleo usado) & 0,82 \\
Ácido oléico & 0,52 \\
Oleato de metila & 0,82 \\
\hline
\end{tabular}

*Condições de análise: sílica como fase estacionária; éter de petróleo:éter etílico:ácido acético, na proporção 80:19:1 como fase móvel e iodo como revelador cromatográfico.

Os sinais encontrados nos espectros de $\mathrm{RMN}{ }^{1} \mathrm{H}$ dos produtos formados, confirmaram a conversão de forma bastante eficiente. $\mathrm{O}$ óleo de soja contém triacilglicerídeos e esses compostos são identificados, no espectro de $\mathrm{RMN}{ }^{1} \mathrm{H}$, pelos sinais em $\delta 4,15$ (dd), 4,30 (dd) e 5,35 (m) que caracterizam os hidrogênios carbinólicos da porção do glicerol esterificado. Esses sinais não foram observados nos espectros dos produtos obtidos, indicando o desaparecimento do material de partida. Além disso, o produto pode ser identificado pela presença de um singleto a $\delta 3,64$ correspondente à presença de ésteres metílicos.

Partindo apenas da quantidade de óleo utilizado na reação (100 $\mathrm{mL}$ ), o rendimento obtido para o biodiesel a partir do óleo in natura e do usado em fritura foi de 89,5 e $88 \mathrm{~mL}$, respectivamente, ou seja, uma taxa de conversão de 89,5 e $88 \%$. Rabelo ${ }^{9}$ realizou reações de transesterificação em pequena escala para determinar o volume de metanol e a massa de hidróxido de potássio, tendo obtido um rendimento de $93 \%$ de biodiesel a partir de $1,5 \mathrm{~g}$ de $\mathrm{KOH}$ e $35 \mathrm{~mL}$ de metanol para $100 \mathrm{~mL}$ de óleo usado. Embora o procedimento envolvendo a reação de transesterificação e as lavagens usados por Rabelo ${ }^{8}$ tenham sido diferentes da nossa proposição, podemos inferir que os rendimentos obtidos em nosso experimento foram satisfatórios.

Os resultados obtidos com o biodiesel produzido a partir do óleo usado em frituras foram similares aos obtidos com o óleo de soja in natura, permitindo deduzir que esses óleos podem ser promissores para a produção do biodiesel, mas convém levar em conta alguns pré-tratamentos que devem ser realizados antes do processo de transesterificação. O óleo, depois de usado, torna-se um resíduo indesejado e sua reciclagem como biocombustível alternativo não só retiraria do meio ambiente um poluente, mas também permitiria a geração de uma fonte alternativa de energia ${ }^{13}$.

A metodologia de obtenção do biodiesel foi usada com os alunos que cursavam a disciplina de Química Orgânica Experimental I. Oito duplas foram formadas, quatro delas utilizaram óleo de soja in natura e as restantes, óleo de soja usado em fritura. Os produtos obtidos também apresentaram aspecto límpido de coloração amarela. A medida da densidade, a análise da cromatoplaca e dos espectros de $\mathrm{RMN}{ }^{1} \mathrm{H}$ para esses produtos foram muito similares aos obtidos nos experimentos-piloto, mostrando a eficiência da reação, bem como a adequação dessa prática alternativa no tempo de 2 aulas práticas de $4 \mathrm{~h}$ cada. Entretanto, perdas durante a execução dos experimentos foram observadas e, conseqüentemente, o rendimento médio da reação foi de $81 \%$.

Finalmente o teste de combustão mostrou que o biodiesel recémpreparado apresentou reação de combustão imediata, cuja chama rica em fuligem negra apresentou um cone de chama totalmente amarelado, diferentemente do observado para o álcool metílico, cujo cone apresentava tonalidade azul. O óleo de soja resistiu ao máximo à reação de combustão sendo, praticamente, um líquido não inflamável. A glicerina destilada também não apresentou combustão.

A compreensão das reações envolvidas nesse experimento foi alcançada através das discussões pré e pós-laboratorial em sala de aula, elaboração de relatórios envolvendo algumas questões, tais como o mecanismo da reação de transesterificação utilizada nesse experimento ${ }^{3,5}$; o mecanismo da reação de transesterificação em meio ácido ${ }^{3,5}$; outras rotas alternativas para produção de ésteres metílicos a partir de ácidos graxos; a utilização de $\mathrm{HCl}$ no procedimento de lavagem; a relação entre os valores de $R_{f}$ com as estruturas dos triacilglicerídeos, ácidos graxos e ésteres metílicos; a razão pela qual se adiciona metanol em excesso; a quantidade necessária de metanol para a reação de transesterificação utilizando 100 mL de óleo de soja (dados: $1 \mathrm{~mol}$ de triacilglicerídeos no óleo de soja: $882 \mathrm{~g}$; densidade do óleo de soja: $0,925 \mathrm{~g} / \mathrm{mL}$; densidade do metanol: $0,79 \mathrm{~g} / \mathrm{mL}$ ); o cálculo da porcentagem do metanol que não reagiu; o conceito de resíduo, rejeito e insumo.

\section{CONCLUSÕES}

O principal objetivo deste trabalho foi preparar uma aula prática na qual o conteúdo referente às reações de esterificação, exigido na ementa do curso, fosse aplicado na obtenção de um produto de grande interesse econômico, utilizando ferramentas comuns em um laboratório de química orgânica. Um dos aspectos positivos observados foi a grande motivação por parte dos alunos ao realizar o experimento devido à discussão nacional sobre as vantagens do uso de biodiesel, uma vez que este é oriundo de uma fonte renovável de energia e polui menos o ambiente. Além disso, os conceitos de resíduo, insumo e rejeito foram introduzidos, aproximando os alunos da terminologia industrial. Mostrou-se também a importância do tratamento adequado de resíduos gerados em reações orgânicas.

\section{MATERIAL SUPLEMENTAR}

Os espectros de $\mathrm{RMN}{ }^{1} \mathrm{H}$ do óleo usado em frituras antes da reação de transesterificação e do biodiesel obtido encontram-se dis- 
poníveis em http://quimicanova.sbq.org.br, na forma de arquivo pdf, com acesso livre.

\section{AGRADECIMENTOS}

Aos Profs. L. A. Cardoso, F. Andrade, N. F. Roque, M. Malta (DCET-UNEB) e aos alunos da disciplina de Química Orgânica Experimental I - QUI 140, da turma do $2^{\circ}$ semestre de 2005 pela dedicação nesta nova prática de ensino.

\section{REFERENCIAS}

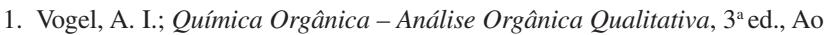
Livro Técnico: Rio de Janeiro, 1985.

2. Soares, B. G.; Souza, N. A.; Pires, D. X.; Química Orgânica: Teoria e Técnicas de Preparação, Purificação e Identificação de Compostos Orgânicos, Ed. Guanabara: Rio de Janeiro, 1988.

3. Meher, L. C.; Sagar, D. V.; Naik, S. N.; Renew. Sustain. Energy Rev. 2004, $10,248$.

4. Ma, F.; Hanna, M. A.; Bioresour. Technol. 1999, 70, 1.

5. Schuchardt, U.; Sercheli, R.; Vargas, R. M.; J. Braz. Chem. Soc. 1998, 9, 199.
6. Pinto, A. C.; Guarieiro, L. L. N.; Rezende, M. J. C.; Ribeiro, N. M.; Torres, E. A.; Lopes, W. A.; Pereira, P. A. P.; de Andrade, J. B.; J. Braz. Chem. Soc. 2005, 16, 1313 .

7. Knothe, G.; Dunn, R. O.; Bagby, M. O.; ACS Symp. Series 1997, 666, 172.

8. http://biodiesel.org/resources/fuelfactsheets, acessada em Fevereiro 2006.

9. http://biodiesel.org.br, acessada em Fevereiro 2006

10. http://www.rbb.ba.gov.br, acessada em Janeiro 2006, Informativo n. 101.

11. Vollhardt, K. P. C.; Schore, N. E.; Química Orgânica: Estrutura e Função, Bookman: Porto Alegre, 2004.

12. http://journeytoforever.org/biodiesel_make.html, acessada em Julho 2005.

13. Costa Neto, P. R.; Rossi, L. F. S.; Zagonel, G. F.; Ramos, L. P.; Quim. Nova 2000, 23, 531 .

14. Felizardo, P.; Correira, M. J. N.; Raposo, I.; Mendes, J. F.; Berkemeier, R.; Bordado, J. M.; Waste Management 2006, 26, 487.

15. Ferrari, R. A.; Oliveira, V. S.; Scabio, A.; Quim. Nova 2005, 1, 19.

16. Freddman, B.; Butterfield, R. O.; Pryde, E.H.; J. Am. Oil Chem. Soc. 1986, 63, 1598.

17. Modi, M. K.; Reddy, J. R. C.; Rao, B. V. S. K.; Prasad, R. B. N.; Biotechnol. Lett. 2006, 28, 637.

18. Tan, T. W.; Nie, K. L.; Wang, F.; Appl. Biochem. Biotechnol. 2006, 128, 109.

19. Rabelo, I. D.; Dissertação de Mestrado, Centro Federal de Educação Tecnológica do Paraná, Brasil, 2001. 
BIODIESEL DE SOJA - REAÇÃO DE TRANSESTERIFICAÇÃO PARA AULAS PRÁTICAS DE QUÍMICA ORGÂNICA

Regina Geris*, Nádia Alessandra Carmo dos Santos, Bruno Andrade Amaral, Isabelle de Souza Maia, Vinicius Dourado Castro e José Roque Mota Carvalho

Instituto de Química, Universidade Federal da Bahia, Campus de Ondina, Rua Barão de Geremoabo, s/n, 40170-290

Salvador - BA, Brasil

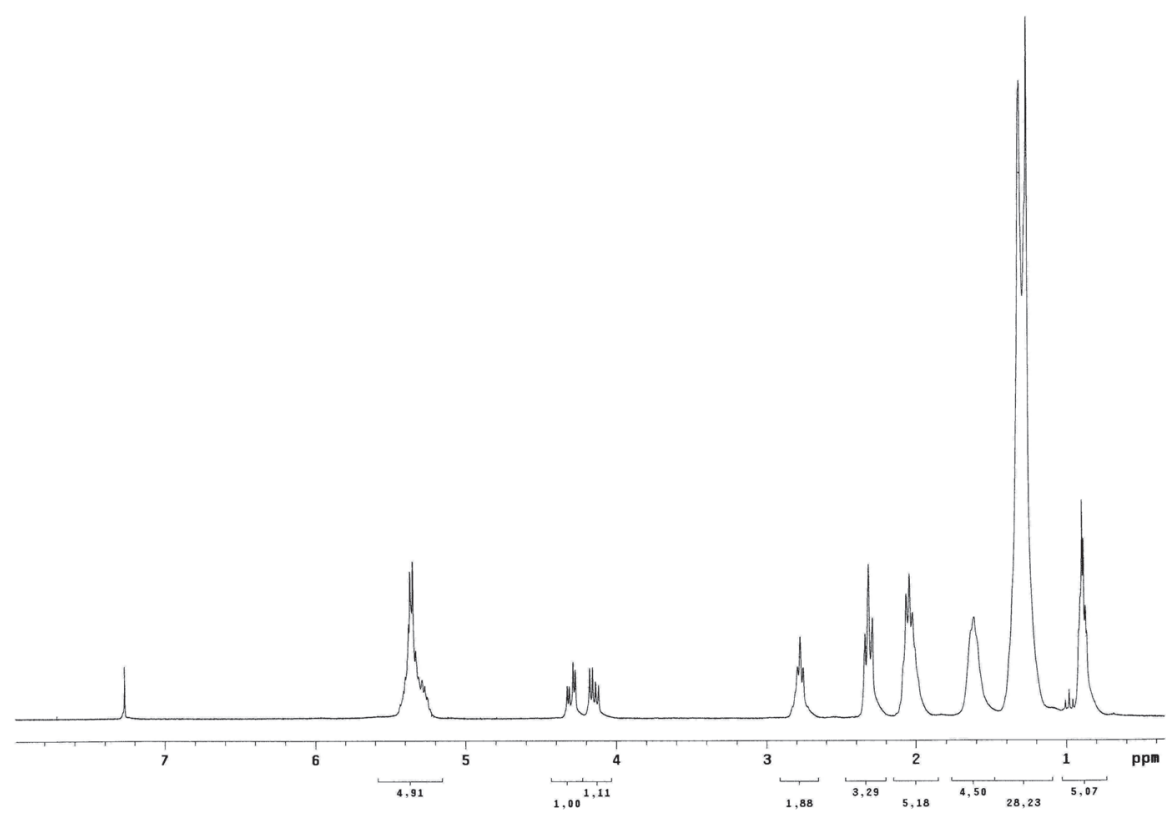

Figura IS. Espectro de $\mathrm{RMN}^{1} \mathrm{H}$ do óleo usado em frituras antes da reação de transesterificação $\left(\mathrm{CDCl}_{3}, 300 \mathrm{MHz}\right)$

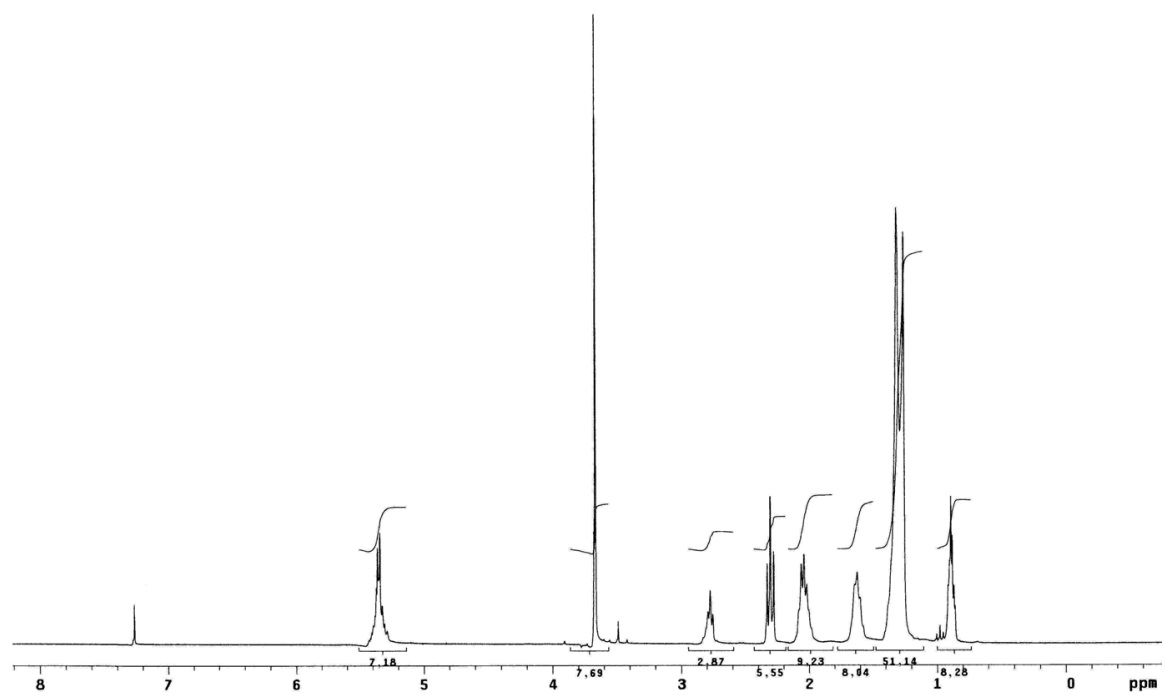

Figura 2S. Espectro de $R M N{ }^{1} \mathrm{H}$ do biodiesel obtido por transesterificação do óleo usado em fritura $\left(\mathrm{CDCl}_{3}, 300 \mathrm{MHz}\right)$ 